\title{
Annual Preparation of Young Weightlifters
}

\author{
Bulku Altin, Ikonomi Edison and Kapedani Kujtim \\ Sports Department, Sports University, Tirana 1000, Albania
}

\begin{abstract}
INTRODUCTION: Weightlifting has its own individual features, where it is important to select new element as well as individual work with them. Ascertaining these specific features of weightlifting sport, trainers are in charge of drafting as accurately as possible the training process, which should be repeatedly realized. PURPOSE OF THE STUDY: It is recognition of the level of technical, physical and anthropometric indicators of young new weightlifters, eliminating the problems arising during the training process to advance the sporting results. MATERIALS AND METHODS: A total of 14 new weightlifters of the five sports clubs were taken into the study for a period of one year (March 2016-March 2017). During the development of national and international activities, we showed their technical results in the style of snatch, clean and jerk, while during training showed the indicators in classical auxiliary exercises with those of strength, weight and body height. The method of comparison for reports technical-strength and weight-height with weightlifters at the European and World level of this age group was used. The data subjected to statistical processing with ANOVA method. RESULTS: The optimum coefficient of ratio: the technique snatch with clean and jerk technique at the international level is $p<0.79-0.80$, compared to our weightlifters in the study, showed that there is oscillation from the optimum $p<0.001$ to $p<$ 0.006. The coefficient weight to height moves $13-16 \mathrm{~cm}$. CONCLUSIONS: This avoidance indicates an inadequate distribution of exercises loads during the training process, most of which take snatch exercises, which do not have a good influence on the performance of the clean and jerk technique results. Loads in classical and classical assistive exercises should be distributed to rights reports for high sports achievements.
\end{abstract}

Key words: Technical level, physical, anthropometric, weightlifting, load, training planning.

\section{Introduction}

Weightlifting requires a continuous process of training and insistent work with the passion of weightlifters and coaches. To create a persistent prospect, special importance should be paid to the training process so that it is more efficient. Analyzing weightlifting in its individual features, it is important to select a new element as well as individual work with them. Determining these specific features of weightlifting sport, trainers are in charge of developing the most accurate training process, which should be followed step by step and weightlifters with their individual work [1].

\section{Purpose of the Study}

It is the recognition of the level of technical, physical and anthropometric indicators of young new

Corresponding author: Kapedani Kujtim, Ph.D., assistant professor, research field: individual sports exercises. weightlifters, eliminating the problems that arise during the training process, to advance sporting results.

\section{Material and Method}

A total of 14 new weightlifters of the five sports clubs were taken into the study for a period of one year (March 2016-March 2017). During the development of national and international activities, we highlighted their technical results in the style snatch and clean jerk while during the exercises we showed the indicators in classical auxiliary exercises with those of strength, weight and body height. The distribution of the load and the volume of exercises during the preparatory period was made using the following elements in percentage: (a) technical snatch + auxiliary exercises $26 \%$, (b) technical clean jerk + auxiliary exercises $24 \%$, (c) lowering legs of the front and back $30 \%$, (d) pulling snatch and clean jerk $10 \%$, (e) individual force exercises $10 \%$ [2]. The method of comparison for technical reports-strength and weight-height with 
weightlifters at the world level of this age group was used. The data were subjected to ANOVA statistical processing.

\section{Results}

Given the technical reports (snatch and clean jerk) as well as the strength technique developed during the training process at our 14 weightlifters, and we have compared them with the best contemporary reports, we built Table 1 .

In Table 1, columns from No. 1 to 11 show the following: (1) The best result achieved in the snatch technique; (2) The best result achieved in the clean jerk technique; (3) The best result at snatch in the foot; (4) The best score on the chest; (5) Better result in lowering for the front legs; (6) The best score on landing back for the legs; (7) Impact report snatch with clean jerk; (8) The ratio of technique to the lowering back clean jerk; (9) Difference from optimal coefficient 0.79-0.80; (10) Difference from the optimal ratio of the Ref. [3]:

$$
\frac{\text { Clean jerk technique }}{\text { Put back }}=(0.80-0.82)
$$

(11) Difference from the optimal of body height to body weight.

\section{Discussion}

Load distribution in classical and classical auxiliary exercises is crucial for high sport achievements. From Table 1, seeing the ratio between the two techniques,

\begin{tabular}{|c|c|c|c|c|c|c|c|c|c|}
\hline$\overline{\mathrm{Nr}}$. & Name & Team & D. B. & Height $(\mathrm{cm})$ & Weight $(\mathrm{Kg})$ & 1 & 2 & 3 & 4 \\
\hline 1 & E.L. & Elbasan & 2002 & 158 & 50 & 77.5 & 90 & 62.5 & 72.5 \\
\hline 2 & A.M & Vllaznia & 2002 & 160 & 56 & 90 & 110 & 75 & 95 \\
\hline 3 & R.S. & Shkumbini & 2000 & 170 & 62 & 97.5 & 120 & 80 & 107.5 \\
\hline 4 & A.G. & Elbasan & 2000 & 167 & 69 & 110 & 132.5 & 95 & 115 \\
\hline 5 & T.S. & Shkumbini & 2003 & 178 & 69 & 90 & 110 & 132.5 & 105 \\
\hline 6 & K.T. & Elbasan & 1999 & $\mathrm{~J} 72$ & 77 & 122.5 & 142.5 & 100 & 120 \\
\hline 7 & V.M. & Partizani & 1996 & 168 & 69 & 120 & 132.5 & 100 & 115 \\
\hline 8 & P.K. & Partizani & 1996 & 170 & 69 & 115 & 135 & 105 & 120 \\
\hline 9 & R.K. & Partizani & 1996 & 171 & 85 & 115 & 140 & 102.5 & 120 \\
\hline 10 & E.B. & Partizani & 1986 & 178 & 77 & 107.5 & 127.5 & 100 & 115 \\
\hline 11 & A.R. & Teuta & 1995 & 160 & 62 & 100 & 120 & 85 & 110 \\
\hline 12 & R.A. & Teuta & 1996 & 171 & 77 & 125 & 150 & 110 & 135 \\
\hline 13 & XH.L. & Teuta & 1996 & 178 & 85 & 130 & 155 & 115 & 140 \\
\hline 14 & M.I. & Vllaznia & 1998 & 190 & 105 & 140 & 155 & 125 & 140 \\
\hline$\overline{\mathrm{Nr}}$ & Name & Team & 5 & 6 & 7 & 8 & 9 & 10 & 11 \\
\hline 1 & E.L. & Elbasan & 95 & 105 & 0.86 & 0.86 & +0.06 & +0.04 & +6 \\
\hline 2 & A.M & Vllaznia & 130 & 150 & 0.82 & 0.73 & +0.02 & -0.07 & +8 \\
\hline 3 & R.S. & Shkumbini & 145 & 162.5 & 0.81 & 0.82 & +0.01 & 0 & +12 \\
\hline 4 & A.G. & Elbasan & 150 & 170 & 0.83 & 0.78 & +0.03 & -0.02 & +4 \\
\hline 5 & T.S. & Shkumbini & 120 & 135 & 0.82 & 0.81 & +0.02 & 0 & +13 \\
\hline 6 & K.T. & Elbasan & 160 & 180 & 0.86 & 0.79 & +0.06 & -0.02 & +4 \\
\hline 7 & V.M. & Partizani & 150 & 180 & 0.83 & 0.73 & +0.03 & -0.08 & +5 \\
\hline 8 & P.K. & Partizani & 150 & 180 & 0.85 & JJ.75 & +0.05 & -0.06 & +6 \\
\hline 9 & R.K. & Partizani & 160 & 170 & 0.82 & 0.70 & +0.02 & -0.11 & -1 \\
\hline 10 & E.B. & Partizani & 150 & 170 & 0.84 & 0.75 & +0.04 & -0.06 & +10 \\
\hline 11 & A.R. & Teuta & 135 & 160 & 0.83 & 0.75 & +0.03 & -0.06 & +2 \\
\hline 12 & R.A. & Teuta & 170 & 200 & 0.84 & 0.78 & +0.04 & -0.03 & +2 \\
\hline 13 & XH.L. & Teuta & 180 & 200 & 0.83 & 0.75 & +0.03 & -0.06 & +5 \\
\hline 14 & M.I. & Vllaznia & 190 & 210 & 0.80 & 0.74 & +0.10 & -0.07 & +1 \\
\hline
\end{tabular}

Table 1 Physical technical indicators of the weightlifter testers. 
the snatch technique clean jerk technique equal to 0.79-0.80, this ratio is optimal for weightlifters of high levels of sports. By comparing this coefficient with our 14 weightlifters in Table 1, we notice that there is a fluctuation from the optimum $p<0.01$ to $p<0.06$. This avoidance of weightlifters from optimum indicates an incorrect distribution of exercise load during the training process. Most of the weightlifters reflect a burden on snatch, which in the future will not have a good impact on the performance of the clean jerk. Take and study the weightlifter E.L. with the coefficient of two techniques is 0.86 and the weight lifting A.M. with coefficient 0.82 (Table 1) E.L. There is a deviation of 0.06 from the optimum ratio. More concretely, the weightlifter snatch technique result is the $77.5 \mathrm{~kg}$ and clean jerk $90 \mathrm{~kg}$, the difference between the two techniques is $12.5 \mathrm{~kg}$, where the optimum should be $17.5 \mathrm{~kg}$. This difference indicates a one-on-one training process, where importance has been given to snatch technique and its auxiliary exercises, leaving the clean jerk exercises behind. The other weightlifter A.M. the ratio between the two techniques snatch and clean jerk moves from the optimum 0.02 , so in this weightlifter the load distribution is in very small errors.

In many weightlifters during the execution of the techniques (snatch and clean jerk) in the race and during the training process are reflected the impetuous, non-dynamic actions, improper driving habits, as a stumbling lift does not take the other lift. These weightlifters reflect the agility as a decisive indicator and not a dynamic force for the growth of sports results. One of the indicators we have analyzed in this study is ratio technique the backstop of legs back. For a high technique, this ratio should be in the range of 0.80 to 0.82. In Table 1 column 8 , the data shown at 14 weightlifters in this report, which we noted above, have a movement from 0.03 to 0.11 . For example, to weightlifter E.I. reflects insufficient force of the muscles of the legs. Avoiding this weightlifter is 0.04 . This indicates that in this weightlifter the load taken for the development of the muscle strength of the legs is small. In some other weightlifters, A.M., R.S., T.S. seeing Table 1 column 10 and by comparing it with the optimal coefficient of 0.80 to 0.82 , we notice that the deviation is 0.07 to 0.11 , indicating that there is a great load in the training process for developing muscle strength of the legs. From our observations, we notice that many trainers prefer trunk muscle exercises, but this method does not guarantee results, as the ratio of the preparation of leg muscles to the trunk muscles reaches the $52 \%$ limit of $48 \%$. Also, during the activities are seen realizations to increase the weights by force, for example, snatch in the legs, clean jerk without technical. Some coaches are hastened to achieve the fastest result of the sports results. Without well-mastered the technique during the training process, they require high scores. For this reason, it is recommended for young weightlifters to have 3 training sessions per week for 10-12 years of age. As the age increases, these sessions increase, but always supported on the basic training principle: "suitability and gradual load". In Table 1, the relationship between body weight and body height does not match the parameters of contemporary weightlifters. The morphological parameters of weightlifters by sport categories are presented in Table 2.

With weightlifting sport, many young people can be taken, but to achieve high-speed results, from the trainer selected weightlifters who have favorable anatomical and physiological construction, as well as an effective training. Looking at international experience, from high world sports achievements body height with body weight are as in Table 2. At 14 weightlifters, making comparisons of weights with body height we have fluctuations moving from $13 \mathrm{~cm}$ to $16 \mathrm{~cm}$. In the first group, where the height of the weightlifters moves from the optimum $1 \mathrm{~cm}$ to $3 \mathrm{~cm}$ does not affect, but it should be noted that at these ages should be predicted the passages from a weight to the next weight. In the second group, where altitude movements are $4 \mathrm{~cm}$ to $13 \mathrm{~cm}$, the trainer's task is to 
Journal of Sports Science 6 (2018) 133-136

doi: 10.17265/2332-7839/2018.02.009

Table 2 The links between weight with height, categories by weight and sport quality [4].

\begin{tabular}{llllll}
\hline Weight & Category 3 & Category 2 & Category 1 & High level & International level \\
$56 \mathrm{~kg}$ & $161.5 \pm 1.3 \mathrm{~cm}$ & $158 \pm 1.2 \mathrm{~cm}$ & $157 \pm 1 \mathrm{~cm}$ & $153.5 \pm 1.2 \mathrm{~cm}$ & $151.5 \pm 0.5 \mathrm{~cm}$ \\
$62 \mathrm{~kg}$ & $166.5 \pm 1.4 \mathrm{~cm}$ & $163 \pm 1.2 \mathrm{~cm}$ & $161 \pm 1 \mathrm{~cm}$ & $158.5 \pm 1 \mathrm{~cm}$ & $157.5 \pm 0.7 \mathrm{~cm}$ \\
$69 \mathrm{~kg}$ & $170 \pm 1.4 \mathrm{~cm}$ & $168 \pm 1.3 \mathrm{~cm}$ & $166 \pm 1 \mathrm{~cm}$ & $164.5 \pm \mathrm{Icm}$ & $163 \pm 0.7 \mathrm{~cm}$ \\
$77 \mathrm{~kg}$ & $174 \pm 1.4 \mathrm{~cm}$ & $172 \pm 1.4 \mathrm{~cm}$ & $171 \pm 1 \mathrm{~cm}$ & $170 \pm 1 \mathrm{~cm}$ & $168 \pm 0.7 \mathrm{~cm}$ \\
$85 \mathrm{~kg}$ & $177 \pm 1.6 \mathrm{~cm}$ & $175 \pm 1.5 \mathrm{~cm}$ & $174 \pm 1 \mathrm{~cm}$ & $173 \pm 1 \mathrm{~cm}$ & $172.5 \pm 0.7 \mathrm{~cm}$ \\
$94 \mathrm{~kg}$ & $180 \pm 1.6 \mathrm{~cm}$ & $178 \pm 1.6 \mathrm{~cm}$ & $177 \pm 1 \mathrm{~cm}$ & $176 \pm 1 \mathrm{~cm}$ & $175 \pm 1 \mathrm{~cm}$ \\
$105 \mathrm{~kg}$ & $183 \pm 1.6 \mathrm{~cm}$ & $180 \pm 1.6 \mathrm{~cm}$ & $178.5 \pm 1.5 \mathrm{~cm}$ & $177 \pm 1.2 \mathrm{~cm}$ & $177 \pm 1 \mathrm{~cm}$ \\
$105 \mathrm{~kg}$ & $185 \pm 2 \mathrm{~cm}$ & $+183 \mathrm{~cm}$ & $+183 \mathrm{~cm}$ & $+183 \mathrm{~cm}$ & $+183 \mathrm{~cm}$ \\
\hline
\end{tabular}

complete a training prognosis with a special training studied in volume and intensity, to increase the muscle volume, to develop a favorable construct for high results in that weight that will compete on weightlifters. In this study, we thought to draw some conclusions to serve the coaches to raise the weightlifting sporting quality [4].

\section{Conclusions}

Load distribution to most weightlifters is not properly defined in classical exercises, classical auxiliaries and strength.

More work needs to be done to increase the speed of classical exercises.

Force during the training period is to develop within optimal limits and not to precede the technique, as this will bring down the speed of movement [5].

Commitment to the acquisition of high technique, is a key factor in achieving high results.

Considering the early age of young boys, they should be very careful in the training methodology, based on the principle of suitability and gradual load.

Avoidance of body weight with body height is important for high sports results.

\section{References}

[1] Karriqi, A., and Haxhihyseni, A. 1998. "Sports Weightlifters Studies." CNSCH National Journal Albaian Sport 6 (1): 12.

[2] Medvedyev, A. S., and Vorobiev, G. 1985. Year Training in Weightlifting. Moscow, Russia: University Publishing House, 38-41.

[3] Williams, P. 2001. "Effects of a Circuit Weight Training Program on the Body Images of College Students." Int. J. Eat Disord. 14 (3): 75-82.

[4] Ferunaj, P. 2003. Weightlifting. Tirana, Albania: University Book House, 49-50, 133-6.

[5] Jorgoni, A. 2007. Methodology of Force Exercise. Tirana, Albania: University Book House, 208-11. 